\title{
An Investigation on Some Mechanical Properties of the Tuft Carpets Produced by Homopolymer, Copolymer and Thermoplastic Polyolefin Mixed Polypropylene Bulked Continuous Filament Yarns
}

\author{
Cemile Emel YAZ ${ }^{1}$ (D) 0000-0003-4463-7815 \\ Cem GÜNEŞOĞLU² (DD 0000-0002-8796-9679 \\ Mehmet TOPALBEKIROĞLU² (D) 0000-0003-4345-8815 \\ ${ }^{1}$ Gaziantep University / Naci Topçuoğlu Vocational School / Gaziantep, Turkey \\ ${ }^{2}$ Gaziantep University / Department of Textile Engineering / Gaziantep, Turkey
}

Corresponding Author: Cemile Emel YAZ, ekirlangic@gantep.edu.tr

\begin{abstract}
There are several parameters that affect the mechanical properties of carpets such as yarn characteristic and carpet construction. Yarn material is one of the most important factors which determine the usage performance of carpets by consumers. This study investigated the mechanical behaviours of carpets produced from polypropylene (PP) bulked continuous filament (BCF) yarns with not only polypropylene homopolymer but also mixing with copolymer (coPP) or thermoplastic polyolefins (TPO). In this respect, nine carpet samples produced by different types of BCF yarns used as pile were examined. Experimental results indicated that mixing polypropylene homopolymer with copolymer or thermoplastic polyolefin resulted with improvement in thickness loss and resilience properties. In addition, thermoplastic polyolefin mixed samples exhibited higher performance compared to those of copolymer, in both dynamic and static loading. PP BCF yarn composition had considerable influences on compressibility behaviours of carpets, whereas there was no significant effect on tuft withdrawal force.
\end{abstract}

\section{ARTICLE HISTORY}

Received: 08.10.2020

Accepted: 10.08.2021

\section{KEYWORDS}

Carpet, BCF yarn, polymer mixing, polypropylene homopolymer, copolymer, thermoplastic polyolefin

\section{INTRODUCTION}

The carpet industry utilises both filament and spun yarns as pile materials. In tufted sector, filament yarns are more popular. All of the filament yarns are bulked continuous filament (BCF) and there is a widespread use of BCF polypropylene (PP) in face-to-face carpets [1]. PP has a handle like wool and also has low specific gravity that provides better cover in the carpet than other pile fibres, thus it is one of the most important pile fibres used in tufted carpets. It also does not absorb water so it resists to waterborne stain, although oily stains may be a problem. In addition, the resilience (elastic recovery) of PP is not as good as that of some other textile fibres, but this can be compensated by increasing the pile density of carpet. The low cost of its monomer is one of the main advantages of PP $[1,2]$. PP yarn used in the machine carpet industry is in generally homopolymer structure which is more rigid than PP copolymer and has better thermal resistance, but impact resistance is low at low temperatures. In addition, ethylenepropylene copolymer structure gives higher elongation and impact resistance in injection molding applications with PP material although it is more expensive than homopolymer [3,

To cite this article: Yaz CE, Güneşoğlu C, Topalbekiroğlu M. 2021. An investigation on some mechanical properties of the tuft carpets produced by homopolymer, copolymer and thermoplastic polyolefin mixed polypropylene bulked continuous filament yarns. Tekstil ve Konfeksiyon, 31(3), 183-194. 
4]. In addition, thermoplastic polyolefins (TPO) are physical blends of rubbers and crystalline thermoplastics. The rubber component is usually an ethylene-propylene rubber (either EPM or EPDM) and the thermoplastics material is polypropylene. The material is characterized by high-impact strength, low density and good chemical resistance [5, 6].

In literature, there are several studies focused on mechanical performances of carpets produced from different types of pile yarns. By many researchers the effects of various parameters, such as pile material, yarn and carpet structure, on the carpet performances were investigated. Most of the studies indicated that due to their characteristic features, different raw materials such as polypropylene, acrylic, nylon or wool have varied effects on carpet deformation behaviours. In addition to this, since the constructional properties, such as pile density and pile height, directly affect the energy of pile yarns, these are defined as decisive parameters on resilience properties of carpets [7-17]. It was also emphasized that, increase pile density and decrease in pile height are the main factors that decrease the deformation [14]. Besides these constructional parameters, the effects of production parameters of $\mathrm{BCF}$ yarn on yarn properties and carpet behaviours were focused on by some researchers. It was noted that yarn characteristics are not only based on structural properties such as cross-section and yarn linear density, but also depend on production parameters like heatsetting temperature, twisting, drawing ratio, etc. [18-21].

As seen from the literature survey, most of the studies investigated the influences of specific raw material characteristics and yarn production parameters on yarn and carpet behaviours. There is an only study which researched polymer mixing in PP BCF. Tavanai et all searched the properties of BCF yarns produced by mixing at different ratios with polyamide 6 to improve the low stretchability properties of PP [22]. However, the effects of BCF yarns on carpet performances were not investigated. Additionally, in literature, there are some studies that had examined the toughening effect of coPP or TPO in blends on samples prepared by injection-molded [23-25]. To the best of our knowledge, there is no research on coPP and TPO usage in $\mathrm{BCF}$ yarn production as pile yarns at carpets. With the aim of determine the effects of polymer mixing on pile yarn deformation behaviours, BCF yarns were produced by at different mixing ratios of $\mathrm{PP}$ homopolymer with coPP or TPO and carpets were manufactured keeping the all other pile and carpet parameters constant. In order to determine experimental results, carpet samples were applied dynamic and short-term static loadings, compression and recovery, hexapod appearance retention and tuft withdrawal force tests.

\section{MATERIAL AND METHOD}

\subsection{Material}

In this study, nine different types of PP BCF yarns, four types of TPO mixed, four types of coPP mixed and a pure PP as a reference, were used as pile with linear density 2100/144 dtex. The compositions of BCF yarns consisted of commercially available polypropylene homopolymer (NATPET H25FBA), polypropylene impact copolymer (coPP) (LyondellBasell Moplen EP548Q) and thermoplastic polyolefin (TPO) (LyondellBasell Adflex Z101H). Mechanical properties of polymers are given in Table 1 . BCF yarns were produced by laboratory scale BCF machine in Kartal Halı Tekstil San. Tic. A.Ş.. The production parameters and the composition percentages of BCF yarns are shown in Table 2 and Table 3, respectively. The heatsetting process parameters of $\mathrm{BCF}$ yarn samples were applied as $135{ }^{\circ} \mathrm{C}$ setting temperature, $450 \mathrm{rpm}$ winding speed, $17.5 \mathrm{~m} / \mathrm{min}$ band speed, 0.75 bar tunnel pressure and 1 minute tunnel waiting time. Carpet samples were produced by Booria Robotuft tufting machine in Royal Halı İplik Tekstil Mobilya San. Tic. A.Ş.. Production parameters were kept constant for all samples, with 210 (pile/cm) pile density and $12 \mathrm{~mm}$ pile height. Tufted samples were dried after applying SBS latex and bonding the second ground fabric (\%100 PET plain weave).

Table 1. Mechanical properties of polymers

\begin{tabular}{cccc}
\hline Property & $\begin{array}{c}\text { Melt Flow } \\
\text { Rate } \\
(\mathbf{g} / \mathbf{1 0 m i n})\end{array}$ & $\begin{array}{c}\text { Flexural } \\
\text { Modulus } \\
(\mathbf{M P a})\end{array}$ & $\begin{array}{c}\text { Impact } \\
\text { Strength } \\
\left(\mathbf{k J} / \mathbf{m}^{\mathbf{2}}\right)\end{array}$ \\
\hline $\begin{array}{c}\text { PP } \\
\text { Homopolymer }\end{array}$ & 25 & 1700 & 2.2 \\
$\begin{array}{c}\text { PP Copolymer } \\
\text { TPO }\end{array}$ & 19 & 1450 & 9 \\
\hline
\end{tabular}

Table 2. Production parameters of BCF yarns

\begin{tabular}{|c|c|c|}
\hline \multicolumn{3}{|c|}{ Extruder Unit } \\
\hline Cabin & Temperature $\left({ }^{\circ} \mathrm{C}\right)$ & Pressure (bar) \\
\hline 1 & 241 & \multirow{6}{*}{105} \\
\hline 2 & 243 & \\
\hline 3 & 245 & \\
\hline 4 & 247 & \\
\hline 5 & 245 & \\
\hline 6 & 247 & \\
\hline \multicolumn{3}{|c|}{ Cooling Unit } \\
\hline \multicolumn{3}{|c|}{ Cooling temperature is $25^{\circ} \mathrm{C}$, lubrication tank pressure 255 bar } \\
\hline \multicolumn{3}{|c|}{ Drawing Unit } \\
\hline Godet & Temperature $\left({ }^{\circ} \mathrm{C}\right)$ & $\begin{array}{c}\text { Cycle Speed } \\
(\mathbf{r p m})\end{array}$ \\
\hline 1 & 25 & 1020 \\
\hline 2 & 90 & 1050 \\
\hline 3 & 138 & 2470 \\
\hline 4 & 37 & 2490 \\
\hline 5 & 145 & 2490 \\
\hline Cabin & - & 1100 \\
\hline Barrel & 145 & 800 \\
\hline
\end{tabular}


Table 3. Composition percentages of BCF yarns

\begin{tabular}{cc}
\hline Sample Code & Pile Yarn (content) \\
\hline $100 \mathrm{PP}$ & $100 \% \mathrm{PP}$ \\
$5 \mathrm{TPO}$ & $5 \% \mathrm{TPO}-95 \% \mathrm{PP}$ \\
$15 \mathrm{TPO}$ & $15 \% \mathrm{TPO}-85 \% \mathrm{PP}$ \\
$20 \mathrm{TPO}$ & $20 \% \mathrm{TPO}-80 \% \mathrm{PP}$ \\
$25 \mathrm{TPO}$ & $25 \% \mathrm{TPO}-75 \% \mathrm{PP}$ \\
$5 \mathrm{coPP}$ & $5 \% \mathrm{coPP}-95 \% \mathrm{PP}$ \\
$15 \mathrm{coPP}$ & $15 \% \mathrm{coPP}-85 \% \mathrm{PP}$ \\
$20 \mathrm{coPP}$ & $20 \% \mathrm{coPP}-80 \% \mathrm{PP}$ \\
$25 \mathrm{coPP}$ & $25 \% \mathrm{coPP}-75 \% \mathrm{PP}$ \\
\hline
\end{tabular}

\subsection{Method}

In order to investigate the effect of coPP and TPO mixed PP $\mathrm{BCF}$ yarns on the mechanical performances of carpets hexapod tumbler, short-term static loading, dynamic loading and compression/recovery tests were performed. All carpet specimens were conditioned with $65 \pm 4 \%$ relative humidity and $20 \pm 2{ }^{\circ} \mathrm{C}$ temperature according to ISO 139:2005 before the tests were conducted.

Thickness loss after dynamic loading was performed to investigate the thickness loss of carpet pile due to the prolonged foot traffic. WIRA dynamic loading machine was used to carry out the test in accordance with the standard of TS 3375 ISO 2094. For this study 50, 100, 200 and 1000 impacts were applied to samples in order to determine the percentage of thickness loss by calculating with Equation (1), where, $h_{0}$ is the initial thickness and $h_{c}$ is the thickness after impacts.

Thickness Loss $(\%)=\frac{h_{0}-h_{c}}{h_{0}} \times 100$

With the aim of determine the resilience performance of carpets, short-term static loading test was performed with WIRA Carpet Static Loading Tester. The specimen was applied $220 \mathrm{kPa}$ pressure for $2 \mathrm{~h}$ and then the load was removed at the end of the duration. The thickness of the samples measured under $2 \pm 0.2 \mathrm{kPa}$ after $15 \mathrm{~min}, 30 \mathrm{~min}$ and 60 min recovery periods, according to the standard of TS 3378. The percentage of resilience was calculated with Equation (2), where, $h_{0}$ is the initial thickness and $h_{c}$ is the thickness after $2 \mathrm{~h}$ compression and $h_{r}$ is the thickness after $60 \mathrm{~min}$ recovery time.

Resilience $(\%)=\frac{h_{r}-h_{c}}{h_{0}-h_{c}} \times 100$

Compression and recovery behaviours of carpets were interpreted at different loading and unloading levels according to the standard of BS 4098 by using WIRA Digital Thickness Gauge. Specimens were applied from 2 kPa to 200 $\mathrm{kPa}$ gradually, and then the weights were removed sequentially from $200 \mathrm{kPa}$ to $2 \mathrm{kPa}$ at $30 \mathrm{~s}$ intervals. The percentage compression recovery of each carpet sample after loading-unloading procedure was measured with Equation (3), where, $t_{2}$ is the thickness under $2 \mathrm{kPa}$ pressure at the beginning of the loading process (Figure 1, point $\mathrm{A}$ ), $t_{r}$ is the thickness at $2 \mathrm{kPa}$ pressure after unloading all weights (Figure 1, point C) and $t_{200}$ is the thickness at $200 \mathrm{kPa}$ pressure (Figure 1, point B).

Percentage Compression Recovery $(\%)=\frac{t_{r}-t_{200}}{t_{2}-t_{200}} \times 100$

Compression work was determined by estimating the area under the loading curve (Figure 1, area ADB). Similarly, recovery work was measured by the area under the unloading curve (Figure 1, area BEC). The percentage work recovery was calculated by the ratio of recovery work to the compression work as shown in Equation (4).

Percentage Work Recovery $(\%)=\frac{\text { Area }_{B E C}}{\text { Area }_{A D B}} \times 100$

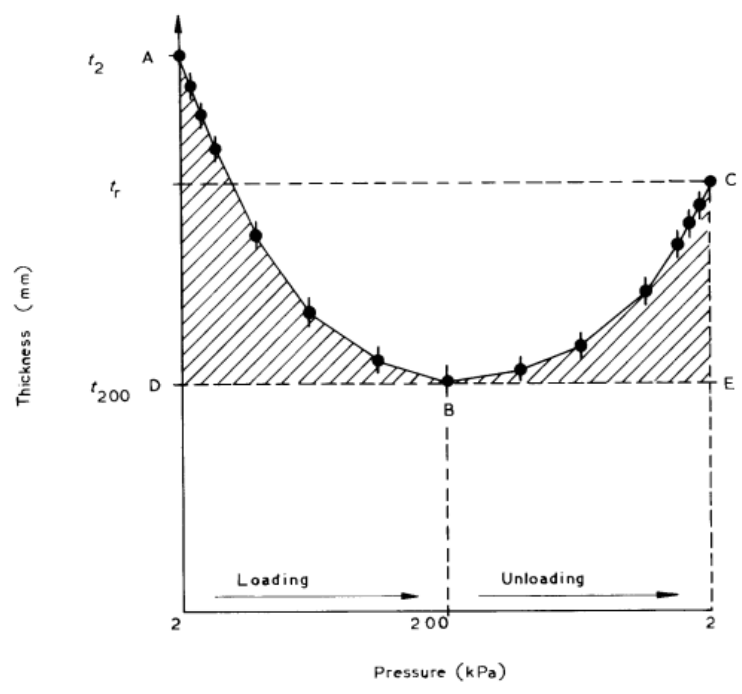

Figure 1. Typical thickness versus pressure curve

Besides thickness loss and resilience determinations, hexapod tumbler test was carried out in order to evaluate the changes in appearance of carpets. Specimens were tested for 4000 revolutions using WIRA Hexapod Tumbler Carpet Tester in accordance with the standard of TS ISO 10361. Assessments of appearance changes were interpreted subjectively depending on the appropriate set of ISO reference scales.

Determination of tuft withdrawal force test was also performed to investigate whether BCF yarn composition has an effect on the tuft retention. Test was done according to the BS ISO 4919:2012 standard, using WIRA Tuft Withdrawal Tensometer device.

In order to determine the statistical importance of content type and \% percentage on carpet performances, two-way ANOVA was performed for TPO or coPP mixed samples. The statistical software package SPSS 25.0 was used to interpret the experimental data. All test results were assessed at $95 \%$ confidence interval. 


\section{RESULTS AND DISCUSSION}

\subsection{Thickness loss after dynamic loading}

Dynamic loading test, which is a simulation of walking on carpet, was performed in the study in order to determine thickness loss after different number of impacts. Percentage thickness loss of carpet samples after 50, 100, 200 and 1000 impacts were calculated by Equation (1) and shown in Figure 2 . The results showed that; 5TPO and 20coPP had lowest and highest thickness loss, respectively. It was also observed that, when the TPO and coPP materials were considered, TPO mixed samples had lower thickness loss than those of coPP and neat PP. It can be said that, TPO's elastic structure provided better impact resistance due to the its higher toughness, as seen from the Table 1, compared to coPP and PP homopolymer. Depending on the results, it was also deduced that, thickness loss increased as the \% percentage increased until $20 \%$, after which it decreased. This situation probably occurred because of the deformed internal structure as $\%$ percentage increased until $20 \%$. However, when the $\%$ percentage reached up to $25 \%$, coPP and TPO contributed more effectively to the impact resistance. Finally, it can be concluded that since the thickness changes of the carpets under impact are related to increase in load carrying capacity; with the addition of coPP and TPO, the load carrying capacity of BCF yarns increased and the thickness loss of carpets produced from these yarns also improved. As the impact level increased thickness loss also increased for all samples.

Table 4 and Table 5 shows mean, standard deviation and $\% \mathrm{CV}$ of the results for all impacts levels and two-way ANOVA results of the TPO or coPP mixed samples for thickness loss under dynamic loading after 1000 impacts, respectively. According to Table 5, it can be said that both content type $(\mathrm{p}=0.000<0.05)$ and $\%$ percentage $(\mathrm{p}=0.035<0.05)$ had statistically significant effect on thickness loss in 95\% confidence interval. In addition, content type $(F=20.672)$ was more effective on thickness loss than $\%$ percentage $(F=3.358)$. No statistically significant interaction was observed between the content type and $\%$ percentage $(\mathrm{p}=0.433>0.05)$.

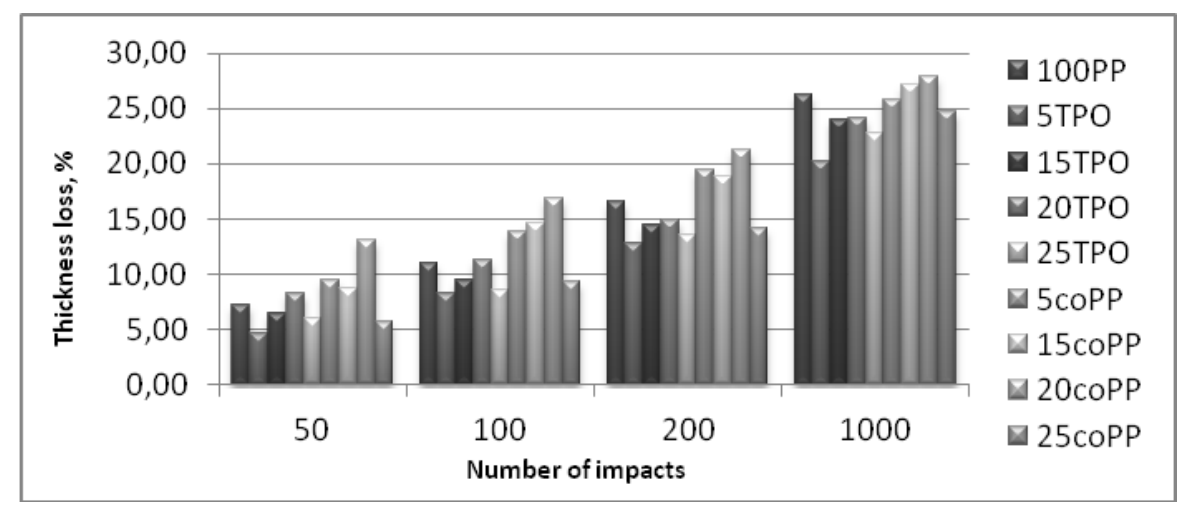

Figure 2. Thickness loss of samples after number of impacts

Table 4. Mean, standard deviation and $\% \mathrm{CV}$ of dynamic loading test results

\begin{tabular}{|c|c|c|c|c|c|c|c|c|c|c|}
\hline \multicolumn{2}{|c|}{ Sample code } & \multirow{2}{*}{$\begin{array}{c}\text { 100PP } \\
7.28\end{array}$} & \multirow{2}{*}{$\begin{array}{c}\text { 5TPO } \\
4.71\end{array}$} & \multirow{2}{*}{$\begin{array}{c}15 \mathrm{TPO} \\
6.42\end{array}$} & \multirow{2}{*}{$\begin{array}{c}\text { 20TPO } \\
8.27\end{array}$} & \multirow{2}{*}{$\frac{25 \mathrm{TPO}}{6.07}$} & \multirow{2}{*}{$\begin{array}{c}\text { 5соPP } \\
9.52\end{array}$} & \multirow{2}{*}{$\frac{15 \operatorname{coPP}}{8.65}$} & \multirow{2}{*}{$\begin{array}{c}\text { 20coPP } \\
13.06\end{array}$} & \multirow{2}{*}{$\frac{25 \mathrm{coPP}}{5.65}$} \\
\hline & Mean & & & & & & & & & \\
\hline $\begin{array}{c}50 \\
\text { impacts }\end{array}$ & SD & 2.75 & 2.16 & 1.78 & 1.82 & 3.09 & 1.06 & 1.97 & 0.76 & 1.81 \\
\hline & $\% \mathrm{CV}$ & 37.76 & 46.09 & 27.83 & 22.10 & 50.89 & 11.16 & 22.88 & 5.84 & 32.05 \\
\hline \multirow{3}{*}{$\begin{array}{c}100 \\
\text { impacts }\end{array}$} & Mean & 10.99 & 8.20 & 9.47 & 11.32 & 8.51 & 13.92 & 14.69 & 16.82 & 9.28 \\
\hline & SD & 1.24 & 1.67 & 1.91 & 2.49 & 2.90 & 2.01 & 0.64 & 0.86 & 2.35 \\
\hline & $\% \mathrm{CV}$ & 11.37 & 20.45 & 20.21 & 22.06 & 34.12 & 14.45 & 4.35 & 5.15 & 25.33 \\
\hline \multirow{3}{*}{$\begin{array}{c}200 \\
\text { impacts }\end{array}$} & Mean & 16.56 & 12.74 & 14.40 & 14.94 & 13.56 & 19.41 & 18.83 & 21.23 & 14.22 \\
\hline & SD & 1.82 & 2.61 & 2.33 & 3.37 & 3.06 & 0.88 & 1.23 & 0.75 & 1.72 \\
\hline & $\% \mathrm{CV}$ & 11.03 & 20.51 & 16.20 & 22.61 & 22.56 & 4.55 & 6.53 & 3.55 & 12.10 \\
\hline \multirow{3}{*}{$\begin{array}{c}1000 \\
\text { impacts }\end{array}$} & Mean & 26.24 & 20.15 & 24.04 & 24.15 & 22.74 & 25.81 & 27.19 & 27.84 & 24.69 \\
\hline & SD & 1.34 & 1.77 & 2.06 & 4.39 & 2.31 & 1.49 & 0.72 & 1.44 & 1.84 \\
\hline & $\% \mathrm{CV}$ & 5.11 & 8.82 & 8.60 & 18.22 & 10.16 & 5.80 & 2.66 & 5.20 & 7.45 \\
\hline
\end{tabular}


Table 5. Two-way ANOVA for thickness loss under dynamic loading after 1000 impact of TPO or coPP mixed samples

\begin{tabular}{|c|c|c|c|c|c|c|}
\hline Source & Type IV Sum of Squares & df & Mean Square & $\mathrm{F}$ & Sig. & Partial Eta Squared \\
\hline Corrected Model & $169.605 \mathrm{a}$ & 7 & 24.229 & 4.799 & 0.002 & 0.583 \\
\hline Intercept & 19327.255 & 1 & 19327.255 & 3828.194 & 0.000 & 0.994 \\
\hline content_type & 104.365 & 1 & 104.365 & 20.672 & 0.000 & 0.463 \\
\hline$\%$ _percentage & 50.866 & 3 & 16.955 & 3.358 & 0.035 & 0.296 \\
\hline content_type $* \%$ _percentage & 14.374 & 3 & 4.791 & 0.949 & 0.433 & 0.106 \\
\hline Error & 121.168 & 24 & 5.049 & - & - & - \\
\hline Total & 19618.028 & 32 & - & - & - & - \\
\hline Corrected Total & 290.773 & 31 & - & - & - & - \\
\hline
\end{tabular}

\subsection{Thickness loss and resilience after short-term static loading}

Thickness loss of samples immediately after removing load and after 15, 30 and $60 \mathrm{~min}(\%)$ recovery periods were determined by short-term static loading. Percentage thickness loss and resilience values were calculated by Equation (1) and Equation (2), shown in Figure 3 and Figure 4, respectively. According to the results which are similar to dynamic loading test, TPO mixed samples exhibited lower thickness loss than those of coPP. Since the toughness of TPO is higher compared to coPP, it was an expected result that to perform lower thickness loss. It was also determined that, mixing coPP with homopolymer did not contribute an improvement on thickness loss. On the other hand, 100PP, with the lowest thickness loss immediately after removing the load, underperformed recovery behavior after $60 \mathrm{~min}$ period when compared to other all samples. This situation means that coPP and TPO addition to homopolymer ensured pile yarn better recovery after a given period of time. 5TPO not only had the proximate value to $100 \mathrm{PP}$ as the thickness loss immediately after removing load, but also showed the lowest thickness loss after 15, 30 and 60 min recovery periods. Contrary, 15 coPP exhibited the highest thickness loss after all recovery periods. For all samples, it was observed that thickness loss decreased by recovery time increases for static loading test.

Resilience can be defined as the ability of pile yarn to return its initial form after loading. Depending on the Figure 4, it was determined that $5 \mathrm{TPO}$ had the highest resilience.
Furthermore, TPO mixed samples had generally higher resilience percentages than those of coPP and 100PP. This was attributed to the higher toughness of TPO material compared to coPP and homopolymer. On the other hand, at low $\%$ percentages, carpets had better thickness loss and resilience performance as seen from the figures. So, it can be concluded that, as the content percentage increased, the mixed samples had become softer due to the lower flexural modulus of coPP and TPO, and resulted in to perform low resistance to static loading by having higher thickness loss, therefore lower resilience.

Mean, standard deviation and \%CV of static loading test results are shown in Table 6. Tables 7 and Table 8 exhibit two-way ANOVA results of TPO or coPP mixed samples for thickness loss after static loading and resilience after $60 \mathrm{~min}$ recovery period, respectively. As seen from Table 7, it can be said that content type $(\mathrm{p}=0.011<0.05)$ had a significant effect, whereas $\%$ percentage $(\mathrm{p}=0.055>0.05)$ was insignificant on thickness loss. Table 8 shows that, both parameters; content type $(\mathrm{p}=0.002<0.05)$ and $\%$ percentage $(\mathrm{p}=0.009<0.05)$ was found to be statistically significant, and also it was seen that the effect of content type $(F=11.929)$ was more than $\%$ percentage $(F=4.535)$, on resilience property. Besides, it was determined from the tables that, the interaction between the parameters was statistically significant $(\mathrm{p}=0.027<0.05$ and $\mathrm{p}=0.005<0.05)$ for thickness loss and resilience properties, respectively.

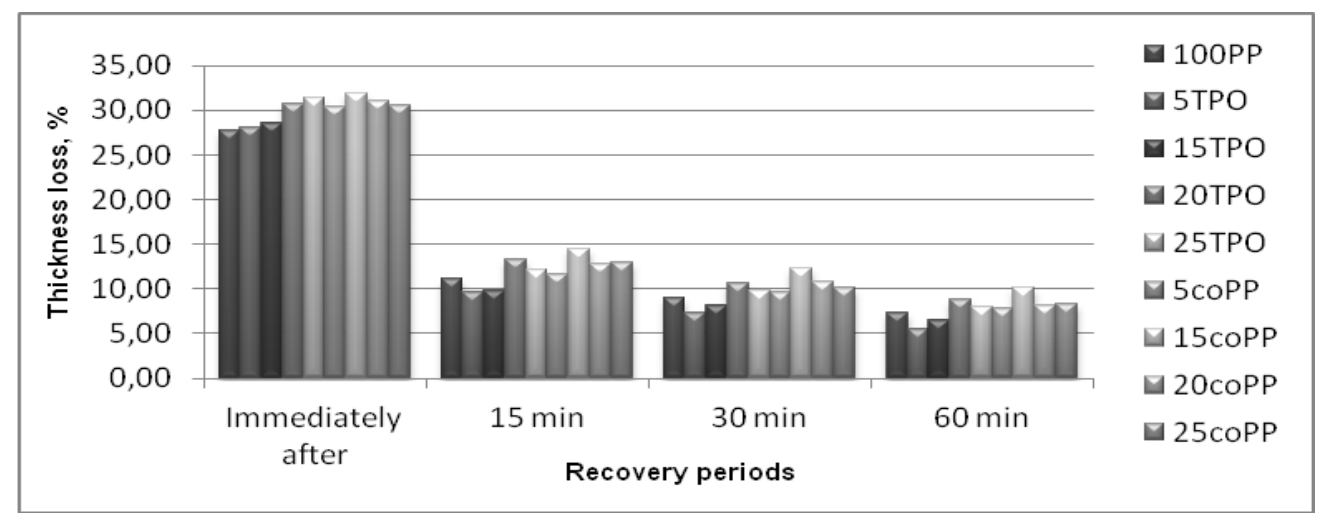

Figure 3. Thickness loss of samples after 2-h loading 


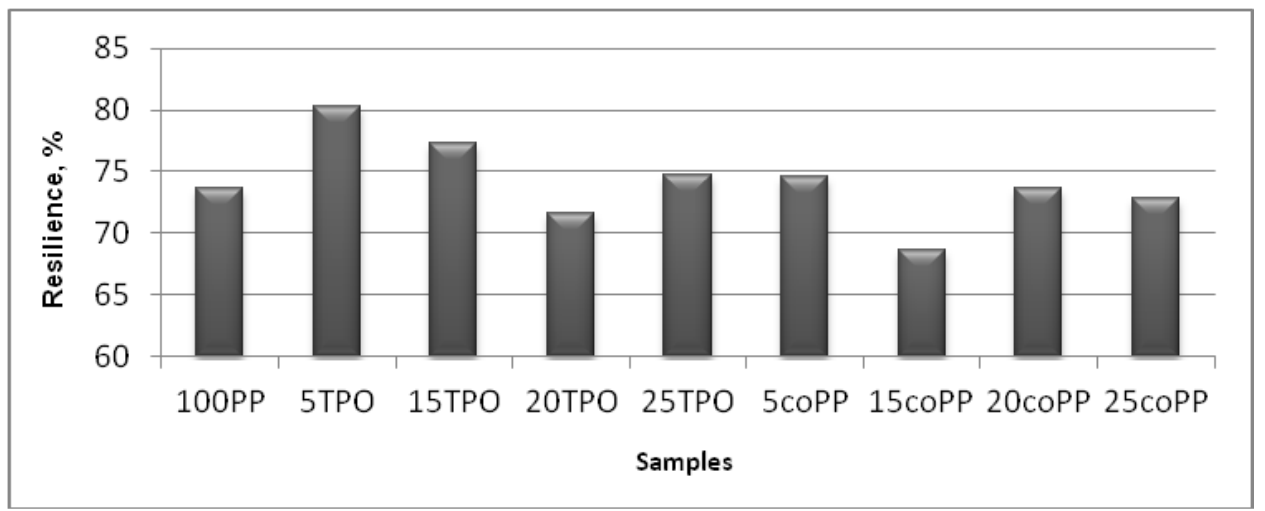

Figure 4. Resilience of samples after 60 min recovery period

Table 6. Mean, standard deviation and \%CV of short-term static loading test results and resilience

\begin{tabular}{|c|c|c|c|c|c|c|c|c|c|c|c|}
\hline & Sample code & & $100 \mathrm{PP}$ & 5 TPO & 15 TPO & 20TPO & 25 TPO & 5 coPP & $15 \mathrm{coPP}$ & 20coPP & 25 coPP \\
\hline \multirow{12}{*}{$\begin{array}{l}\text { Short- } \\
\text { term } \\
\text { static } \\
\text { loading }\end{array}$} & \multirow{3}{*}{$\begin{array}{c}\text { Immediately } \\
\text { after }\end{array}$} & Mean & 27.81 & 28.06 & 28.50 & 30.64 & 31.44 & 30.39 & 31.82 & 31.06 & 30.53 \\
\hline & & SD & 1.27 & 2.39 & 3.06 & 4.27 & 0.63 & 4.87 & 4.32 & 2.12 & 1.65 \\
\hline & & $\% \mathrm{CV}$ & 4.56 & 8.53 & 10,74 & 13,95 & 2,00 & 16,02 & 13,57 & 6,83 & 5,41 \\
\hline & \multirow{3}{*}{$15 \mathrm{~min}$} & Mean & 11.07 & 9.66 & 9.77 & 13.32 & 12.12 & 11.67 & 14.49 & 12.85 & 12.88 \\
\hline & & SD & 0.83 & 1.13 & 1.35 & 3.90 & 0.37 & 2.24 & 1.47 & 1.70 & 1.48 \\
\hline & & $\% \mathrm{CV}$ & 7.54 & 11.71 & 13.86 & 29.29 & 3.01 & 19.20 & 10.17 & 13.21 & 11.52 \\
\hline & \multirow{3}{*}{$30 \mathrm{~min}$} & Mean & 8.99 & 7.31 & 8.12 & 10.62 & 9.81 & 9.61 & 12.34 & 10.82 & 10.14 \\
\hline & & SD & 0.91 & 1.27 & 1.12 & 3.61 & 0.67 & 1.97 & 2.75 & 1.12 & 1.90 \\
\hline & & $\% \mathrm{CV}$ & 10.14 & 17.33 & 13.82 & 33.97 & 6.81 & 20.51 & 22.30 & 10.37 & 18.69 \\
\hline & \multirow{3}{*}{$60 \mathrm{~min}$} & Mean & 7.32 & 5.52 & 6.48 & 8.87 & 7.94 & 7.73 & 10.08 & 8.17 & 8.31 \\
\hline & & SD & 0.93 & 0.50 & 1.12 & 2.85 & 0.47 & 1.72 & 2.30 & 0.91 & 1.39 \\
\hline & & $\% \mathrm{CV}$ & 12.76 & 8.99 & 17.23 & 32.14 & 5.90 & 22.28 & 22.78 & 11.17 & 16.69 \\
\hline \multirow{3}{*}{\multicolumn{2}{|c|}{ Resilience }} & Mean & 73.62 & 80.26 & 77.32 & 71.59 & 74.74 & 74.54 & 68.65 & 73.69 & 72.88 \\
\hline & & SD & 3.70 & 1.42 & 2.57 & 5.94 & 1.32 & 3.45 & 3.51 & 2.05 & 3.13 \\
\hline & & $\% \mathrm{CV}$ & 5.02 & 1.78 & 3.33 & 8.30 & 1.77 & 4.63 & 5.12 & 2.78 & 4.30 \\
\hline
\end{tabular}

Table 7. Two-way ANOVA for thickness loss after static loading of TPO or coPP mixed samples

\begin{tabular}{lcccccc}
\hline Source & Type IV Sum of Squares & df & Mean Square & F & Sig. & Partial Eta Squared \\
\hline Corrected Model & $68.090 \mathrm{a}$ & 7 & 9.727 & 3.736 & 0.005 \\
Intercept & 2488.506 & 1 & 2488.506 & 955.677 & 0.000 \\
content_type & 18.824 & 1 & 18.824 & 7.229 & 0.011 \\
\%_percentage & 21.989 & 3 & 7.330 & 2.815 & 0.055 \\
content_type *\%_percentage & 27.277 & 3 & 9.092 & 3.492 & 0.027 \\
Error & 83.325 & 32 & 2.604 & - & - \\
Total & 2639.921 & 40 & - & - & - \\
Corrected Total & 151.415 & 39 & - & - & - \\
\hline
\end{tabular}

Table 8. Two-way ANOVA for resilience after $60 \mathrm{~min}$ recovery period of static loading of TPO or coPP mixed samples

\begin{tabular}{|c|c|c|c|c|c|c|}
\hline Source & Type IV Sum of Squares & $\mathrm{df}$ & Mean Square & $\mathrm{F}$ & Sig. & Partial Eta Squared \\
\hline Corrected Model & $432.872 \mathrm{a}$ & 7 & 61.839 & 5.878 & 0.000 & 0.563 \\
\hline Intercept & 220277.543 & 1 & 220277.543 & 20938.975 & 0.000 & 0.998 \\
\hline content_type & 125.493 & 1 & 125.493 & 11.929 & 0.002 & 0.272 \\
\hline$\%$ _percentage & 143.121 & 3 & 47.707 & 4.535 & 0.009 & 0.298 \\
\hline content_type $* \%$ _percentage & 164.258 & 3 & 54.753 & 5.205 & 0.005 & 0.328 \\
\hline Error & 336.639 & 32 & 10.520 & - & - & - \\
\hline Total & 221047.055 & 40 & - & - & - & - \\
\hline Corrected Total & 769.512 & 39 & - & - & - & - \\
\hline
\end{tabular}




\subsection{Compression and recovery}

Percentage compression recovery and percentage work recovery of carpets were calculated by Eq. (3) and Eq. (4) and given in Figure 5 and Figure 6, respectively. Compression recovery can be defined as the pile yarn tends to return to its initial shape after loading-unloading As seen from the Figure 5, percentage compression recovery decreased as the content percentage increased, for the mixed samples. This was an expected result that, at lower mixing percentages the mixed samples had comparable compression recovery with $100 \mathrm{PP}$, but as far as at higher mixing ratios the samples performed lower recovery, as a result of reduced rigidity of pile yarns. In consideration with TPO and coPP materials, it was deduced that, the higher flexural modulus of coPP provided higher stiffness and because of that, coPP mixed samples had generally higher compression recovery than those of TPO, after continuing loading-unloading. On the other hand, since the TPO is a softer material due to its significantly lower bending rigidity, TPO mixed samples had lower compression recovery, in other word they deformed easier than 100PP. Additionally, since the flexural modulus of coPP material is closer to that of PP homopolymer, coPP blends did not become softer as much as TPO blends, so the deformation was observed more limited under continuing loading. Finally, it can also be said that, since the flexural modulus of PP homopolymer is higher compared to other polymer, mixed samples generally performed lower compression recovery.

Percentage work recovery generally determines the resistance of carpets to compression. As shown in Figure 6, TPO mixed samples had higher resistance to compression than those of coPP. This situation was attributed TPO's highimpact strength characteristic or in other word higher toughness, due to the rubber component in its structure. Both coPP and TPO polymers have ethylene units in their structure, Furthermore, TPO has elastomer properties due to the rubber components. So its toughness is much more than that of coPP. Consequently, it can be said that, the higher toughness resulted in higher resistance to compression. In addition, it was also observed from the figure that, the increased mixing ratio enhanced more effectively the work recovery.

Compression work is a measure of compressibility of carpets, in other word; it can be defined as the amount of work done for compression of pile yarns. Figure 7, which represents the compression work of samples, showed that, coPP mixed samples had higher values than those of TPO which is softer than coPP. The flexural modulus of coPP material was significantly higher than that of TPO and slightly lower than that of homopolymer. In practical, it is known that, the higher the flexural modulus of a material, the harder it is to bend. For this reason, the lower stiffness of TPO caused the mixed samples to absorb lower energy compared to coPP mixed samples, during compression period. Besides, it was determined that, mixing coPP with homopolymer did not contribute the compression work significantly.

Recovery work, a measure of released energy after the load is removed, can be defined as the amount of work done for recovery of the piles to their initial position. The recovery work of samples are given in Figure 8. As seen from the figure, similar to compression work results, coPP mixed samples had higher values than those of TPO. This means that, TPO mixed samples absorbed and released lower energy compared to coPP samples because of its lower rigidity, during compression and recovery periods.

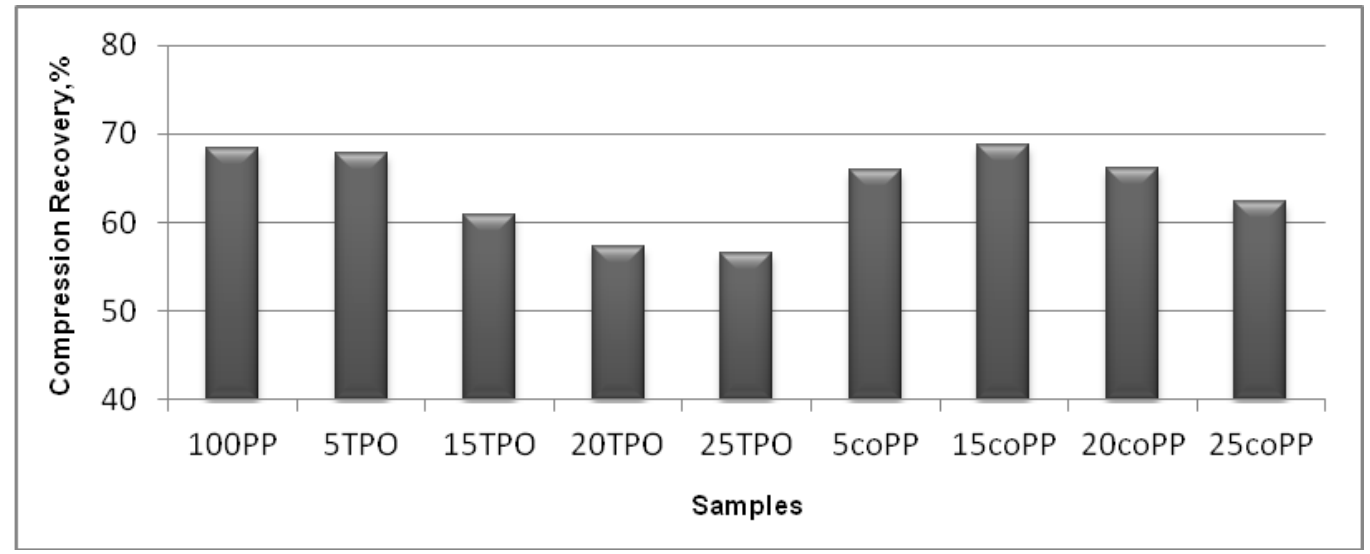

Figure 5. Percentage compression recovery of samples 


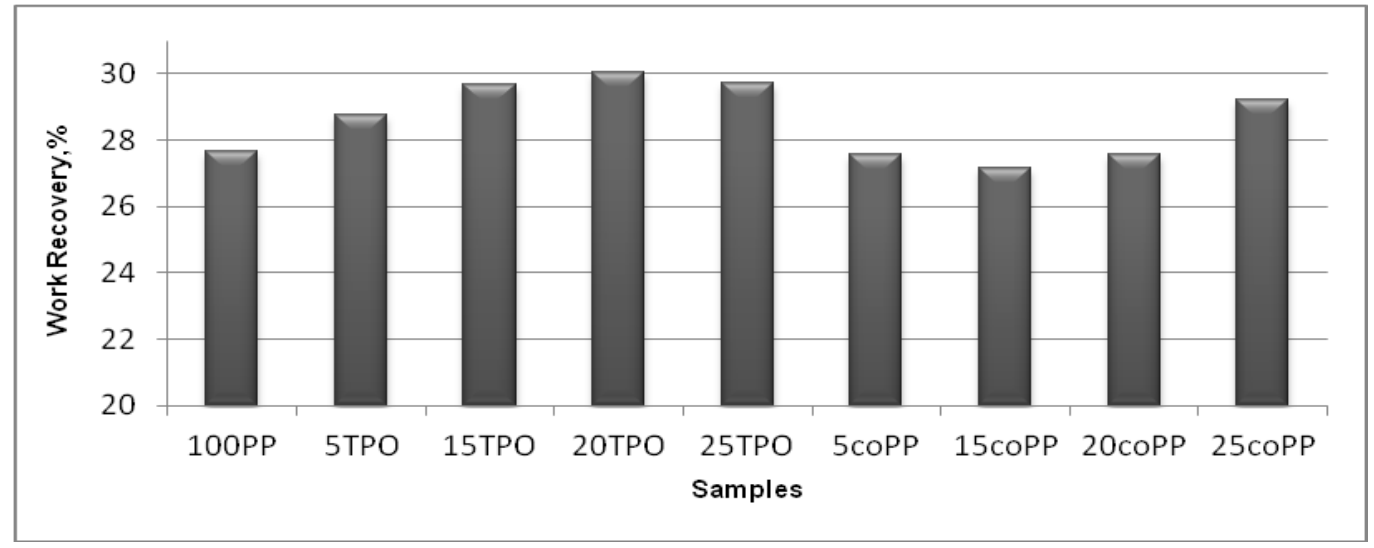

Figure 6. Percentage work recovery of samples

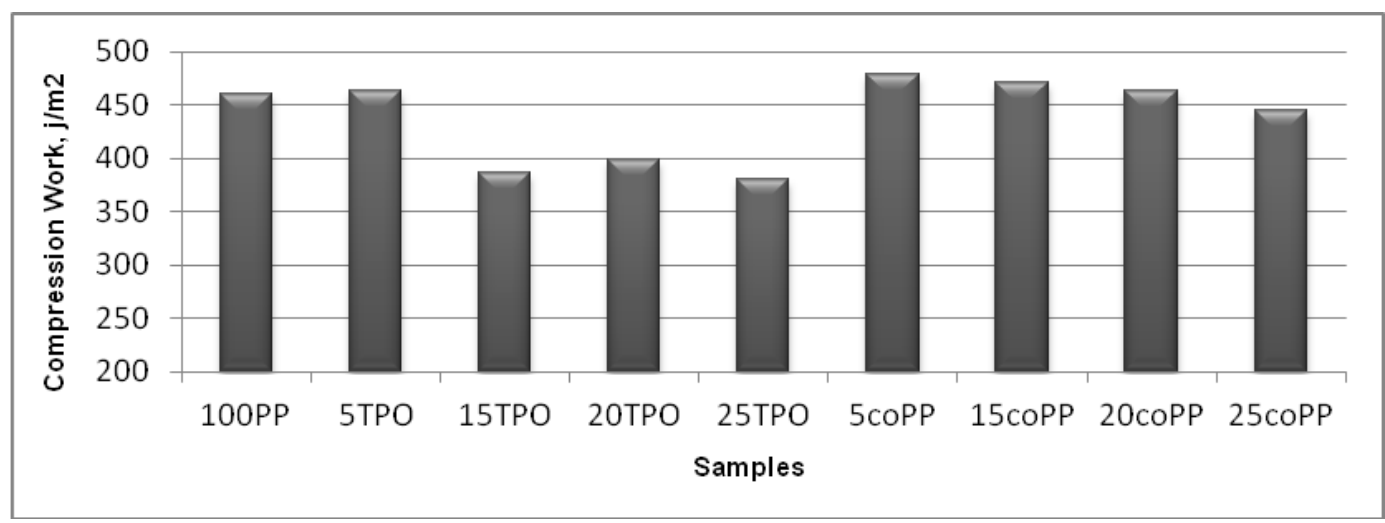

Figure 7. Compression work of samples

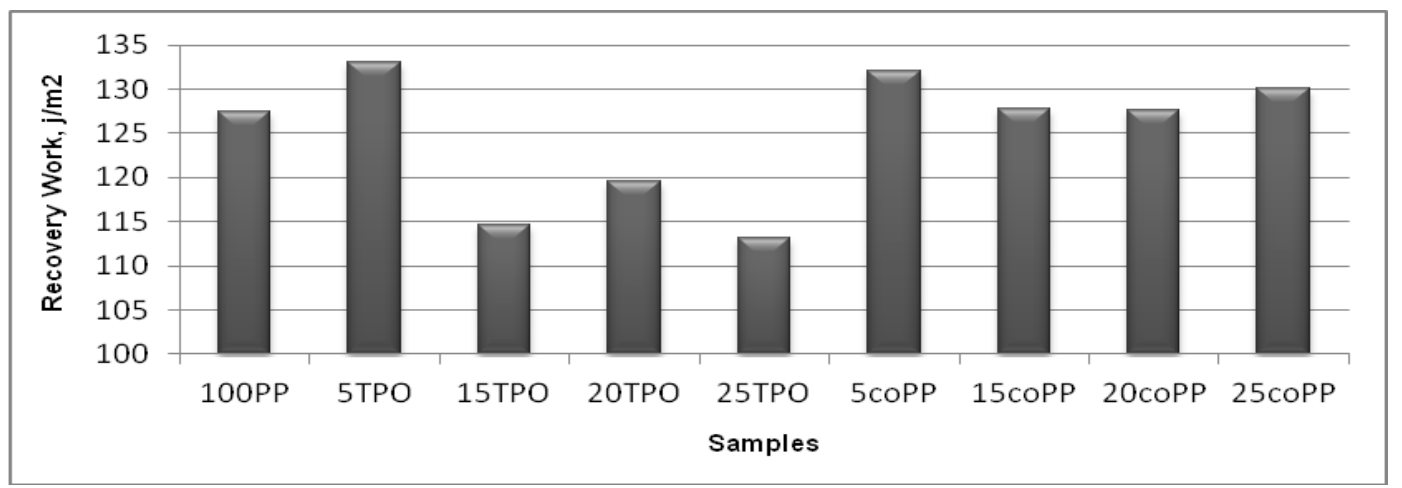

Figure 8. Recovery work of samples

Table 9 exhibits mean, standard deviation and \%CV of the compression and recovery test results. Two-way ANOVA results of TPO or coPP mixed samples for percentage compression recovery, percentage work recovery, compression work and recovery work are shown in Table 10Table 13, respectively. According to the Table 10 and Table 11 , both parameters; content type $(\mathrm{p}=0.002<0.05$ and $\mathrm{p}=0.000<0.05)$ and $\%$ percentage $(\mathrm{p}=0.012<0.05$ and $\mathrm{p}=0.040<0.05)$ had statistically significant effect; besides, content type was more effective than \% percentage, $(F=10.800>F=4.286$ and $F=26.460>F=3.108)$, on percentage compression recovery and percentage work recovery, respectively. No statistically significant interaction was observed between the parameters $(p=0.088>0.05$ and $\mathrm{p}=0.066>0.05)$ from Table 10 and Table 11 . As seen from the Table 12 and Table 13, both content type $(p=0.000<0.05$ and $\mathrm{p}=0.000<0.05)$ and $\%$ percentage $(\mathrm{p}=0.000<0.05$ and $\mathrm{p}=0.004<0.05$ ) factors were statistically significant on compression work and recovery work. It was also seen from the tables that; the effect of content type was higher than that of $\%$ percentage $(F=65.873>F=12.116 \quad$ and $F=16.884>F=5.408)$ on compression work and recovery work. Besides, it was determined that the interaction between content type and \% percentage was statistically significant $(\mathrm{p}=0.013<0.05$ and $\mathrm{p}=0.049<0.05)$ for work of compression and recovery, respectively. 
Table 9. Mean, standard deviation and \% CV compression and recovery test results

\begin{tabular}{ccccccccccc}
\hline \multicolumn{2}{c}{ Sample code } & 100PP & 5TPO & 15TPO & 20TPO & 25TPO & 5coPP & 15coPP & 20coPP & 25coPP \\
\hline $\begin{array}{c}\text { Percentage } \\
\text { compression } \\
\text { recovery }\end{array}$ & Mean & 68.44 & 67.81 & 60.88 & 57.19 & 56.52 & 65.95 & 68.75 & 66.04 & 62.45 \\
& SD & 3.93 & 3.29 & 6.59 & 4.04 & 2.39 & 4.02 & 4.26 & 6.55 & 6.80 \\
\hline $\begin{array}{c}\text { Percentage } \\
\text { work }\end{array}$ & Mean & 27.68 & 28.72 & 29.69 & 30.04 & 29.70 & 27.63 & 27.12 & 27.55 & 29.24 \\
recovery & SD & 0.55 & 0.38 & 0.57 & 1.12 & 0.68 & 1.48 & 0.92 & 1.48 & 0.96 \\
\hline \multirow{2}{*}{$\begin{array}{c}\text { Compression } \\
\text { work }\end{array}$} & Mean & 460.90 & 462.75 & 386.17 & 398.07 & 380.91 & 479.06 & 470.96 & 463.09 & 445.16 \\
& SD & 23.51 & 26.24 & 28.56 & 10.78 & 23.66 & 32.11 & 20.69 & 8.65 & 17.67 \\
\hline \multirow{2}{*}{$\begin{array}{c}\text { Recovery } \\
\text { work }\end{array}$} & Mean & 127.52 & 132.98 & 114.62 & 119.53 & 113.20 & 132.01 & 127.82 & 127.67 & 130.11 \\
& SD & 5.96 & 8.91 & 7.59 & 3.54 & 8.63 & 3.30 & 8.43 & 9.07 & 4.74 \\
\hline
\end{tabular}

Table 10. Two-way ANOVA for percentage compression recovery of TPO or coPP mixed samples

\begin{tabular}{lcccccc}
\hline Source & Type IV Sum of Squares & df & Mean Square & F & Sig. & Partial Eta Squared \\
\hline Corrected Model & $770.272 \mathrm{a}$ & 7 & 110.039 & 4.399 & 0.002 & 0.490 \\
Intercept & 159788.561 & 1 & 159788.561 & 6388.153 & 0.000 & 0.995 \\
content_type & 270.140 & 1 & 270.140 & 10.800 & 0.002 & 0.252 \\
\%_percentage & 321.608 & 3 & 107.203 & 4.286 & 0.012 & 0.287 \\
content_type *\%_percentage & 178.524 & 3 & 59.508 & 2.379 & 0.088 & 0.182 \\
Error & 800.424 & 32 & 25.013 & - & - & - \\
Total & 161359.258 & 40 & - & - & - & - \\
Corrected Total & 1570.697 & 39 & - & - & - & - \\
\hline
\end{tabular}

Table 11. Two-way ANOVA for percentage work recovery of TPO or coPP mixed samples

\begin{tabular}{|c|c|c|c|c|c|c|}
\hline Source & Type IV Sum of Squares & df & Mean Square & $\mathrm{F}$ & Sig. & Partial Eta Squared \\
\hline Corrected Model & $45.308 \mathrm{a}$ & 7 & 6.473 & 6.245 & 0.000 & 0.577 \\
\hline Intercept & 32979.752 & 1 & 32979.752 & 31821.758 & 0.000 & 0.999 \\
\hline content_type & 27.423 & 1 & 27.423 & 26.460 & 0.000 & 0.453 \\
\hline$\%$ _percentage & 9.662 & 3 & 3.221 & 3.108 & 0.040 & 0.226 \\
\hline content_type $* \%$ _percentage & 8.223 & 3 & 2.741 & 2.645 & 0.066 & 0.199 \\
\hline Error & 33.164 & 32 & 1.036 & - & - & - \\
\hline Total & 33058.225 & 40 & - & - & - & - \\
\hline Corrected Total & 78.473 & 39 & - & - & - & - \\
\hline
\end{tabular}

Table 12. Two-way ANOVA for compression work of TPO or coPP mixed samples

\begin{tabular}{|c|c|c|c|c|c|c|}
\hline Source & Type IV Sum of Squares & df & Mean Square & $\mathrm{F}$ & Sig. & Partial Eta Squared \\
\hline Corrected Model & $57830.356 a$ & 7 & 8261.479 & 16.407 & 0.000 & 0.782 \\
\hline Intercept & 7595963.521 & 1 & 7595963.521 & 15085.493 & 0.000 & 0.998 \\
\hline content_type & 33168.673 & 1 & 33168.673 & 65.873 & 0.000 & 0.673 \\
\hline$\%$ _percentage & 18302.461 & 3 & 6100.820 & 12.116 & 0.000 & 0.532 \\
\hline content_type $* \%$ _percentage & 6359.222 & 3 & 2119.741 & 4.210 & 0.013 & 0.283 \\
\hline Error & 16112.887 & 32 & 503.528 & - & - & - \\
\hline Total & 7669906.763 & 40 & - & - & - & - \\
\hline Corrected Total & 73943.243 & 39 & - & - & - & - \\
\hline
\end{tabular}


Table 13. Two-way ANOVA for recovery work of TPO or coPP mixed samples

\begin{tabular}{lcccccc}
\hline Source & Type IV Sum of Squares & df & Mean Square & F & Sig. & Partial Eta Squared \\
\hline Corrected Model & $2152.328 \mathrm{a}$ & 7 & 307.475 & 5.981 & 0.000 & 0.567 \\
Intercept & 622470.065 & 1 & 622470.065 & 12108.495 & 0.000 & 0.997 \\
content_type & 867.972 & 1 & 867.972 & 16.884 & 0.000 & 0.345 \\
\%_percentage & 834.078 & 3 & 278.026 & 5.408 & 0.004 & 0.336 \\
content_type *\%_percentage & 450.278 & 3 & 150.093 & 2.920 & 0.049 & 0.215 \\
Error & 1645.047 & 32 & 51.408 & - & - & - \\
Total & 626267.440 & 40 & - & - & - & - \\
Corrected Total & 3797.375 & 39 & - & - & - & - \\
\hline
\end{tabular}

\subsection{Hexapod appearance retention assessment}

Texture appearance retention levels of samples after 4000 revolutions were assessed subjectively depending on the appropriate reference scale and shown in Figure 9. According to the results, the highest and lowest appearance retention grades were obtained by $15 \mathrm{coPP}$ and the $15 \mathrm{TPO}$, respectively. Contrary to the results of dynamic and static loading tests, it was determined that TPO mixed samples exhibited lower performance in terms of appearance retention than those of coPP. As mentioned before, TPO is a softer material compared to coPP. So this structural property caused TPO mixed samples to have lower ability of appearance retention than those of coPP. On the other hand, it was observed that \% percentage has no regular tendency on appearance retention of samples.

Table 14 and Table 15 exhibits mean, standard deviation, $\% \mathrm{CV}$ and two-way ANOVA results of TPO or coPP mixed samples for hexapod appearance retention levels, respectively. Depending on the Table 15, it can be seen that; content type had a statistically significant effect $(\mathrm{p}=0.001<0.05)$, whereas $\%$ percentage was found to be statistically insignificant $(\mathrm{p}=0.705>0.05)$, on hexapod appearance retention. Additionally, no statistically significant interaction was observed between the parameters $(\mathrm{p}=0.172>0.05)$ from the table.

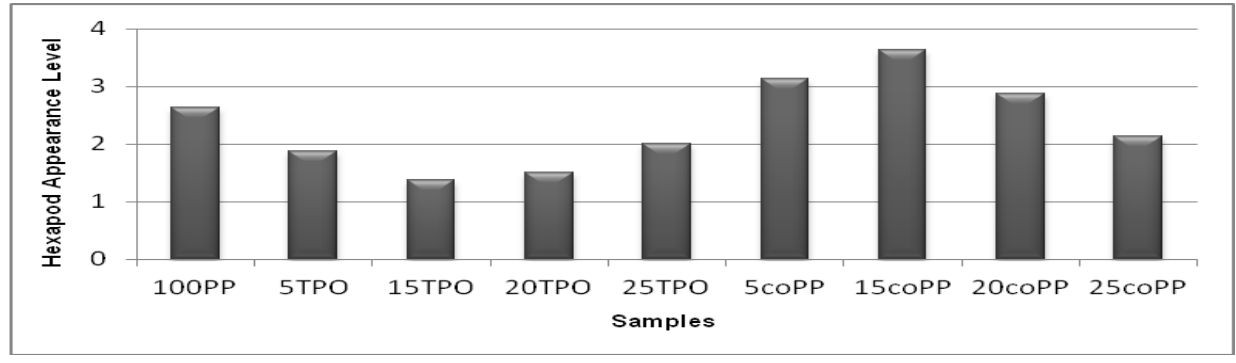

Figure 9. Appearance retention levels of samples

Table 14. Mean, standard deviation and $\% \mathrm{CV}$ of hexapod appearance retention results

\begin{tabular}{ccccccccccc}
\hline \multicolumn{2}{c}{ Sample code } & 100PP & 5TPO & 15TPO & 20TPO & 25TPO & 5coPP & 15coPP & 20coPP & 25coPP \\
\hline \multirow{4}{*}{ Hexapod } & Mean & 2.625 & 1.875 & 1.375 & 1.500 & 2.000 & 3.125 & 3.625 & 2.875 & 2.125 \\
& SD & 1.03 & 0.85 & 0.75 & 1.00 & 1.00 & 0.94 & 0.75 & 0.85 & 1.10 \\
& \%CV & 39.26 & 45.54 & 54.54 & 66.66 & 50.00 & 30.28 & 20.68 & 29.70 & 52.17 \\
\hline
\end{tabular}

Table 15. Two-way ANOVA for hexapod appearance retention of TPO or coPP mixed samples

\begin{tabular}{lcccccc}
\hline Source & Type IV Sum of Squares & df & Mean Square & F & Sig. & Partial Eta Squared \\
\hline Corrected Model & $18.250 \mathrm{a}$ & 7 & 2.607 & 3.109 & 0.018 & 0.476 \\
Intercept & 171.125 & 1 & 171.125 & 204.075 & 0.000 & 0.895 \\
content_type & 12.500 & 1 & 12.500 & 14.907 & 0.001 & 0.383 \\
\%_percentage & 1.188 & 3 & 0.396 & 0.472 & 0.705 & 0.056 \\
content_type*\%_percentage & 4.563 & 3 & 1.521 & 1.814 & 0.172 & 0.185 \\
Error & 20.125 & 24 & 0.839 & - & - & - \\
Total & 209.500 & 32 & - & - & - & - \\
Corrected Total & 38.375 & 31 & - & - & - & - \\
\hline
\end{tabular}




\subsection{Tuft withdrawal force}

Results of tuft withdrawal force of carpet samples is given Figure 10. It was determined that the tuft withdrawal forces of the samples did not show a significant difference with respect to the mixing of materials with different types and quantities. Depending on the results, it was evaluated that, measurements had high variation due to the unevenness of latex applied to carpet samples. In addition, no linear relationship was observed between content type and percentage of mixes.

Mean, standard deviation, \% CV of and two-way ANOVA results of TPO or coPP mixed samples for tuft withdrawal force are shown in Table 16 and Table 17, respectively. As it is seen from the table, both content type $(\mathrm{p}=0.339>0.05)$ and $\%$ percentage $(\mathrm{p}=0.230>0.05)$ were detected statistically insignificant on tuft withdrawal force.

\section{CONCLUSION}

Depending on the dynamic and static loading test results, it was concluded that TPO mixed samples had generally lower thickness loss than those of coPP and neat PP. Furthermore, for both loading tests it was revealed that, mixing 5\% TPO to homopolymer performed the best result in terms of thickness loss and resilience. As the \% percentage increased for both mix type, thickness loss also increased, whereas resilience decreased. This is a desirable situation with regard to cost of production, because coPP and TPO are more expensive than PP homopolymer.

According to the compression and recovery test results, TPO mixed samples had lower values than those of coPP, for work of compression and recovery. This was attributed TPO's softer structure due to the its lower flexural modulus (bending rigidity) compared to coPP affected the work done, therefore TPO absorbed lower energy when it was compressed, and so released lower energy after the load was removed. Additionally, coPP mixed samples had generally higher compression recovery than those of TPO, since the higher flexural modulus of coPP ensured higher stiffness. In addition, TPO mixed samples had higher resistance to compression than those of coPP. This situation was attributed TPO's high-impact strength characteristic or

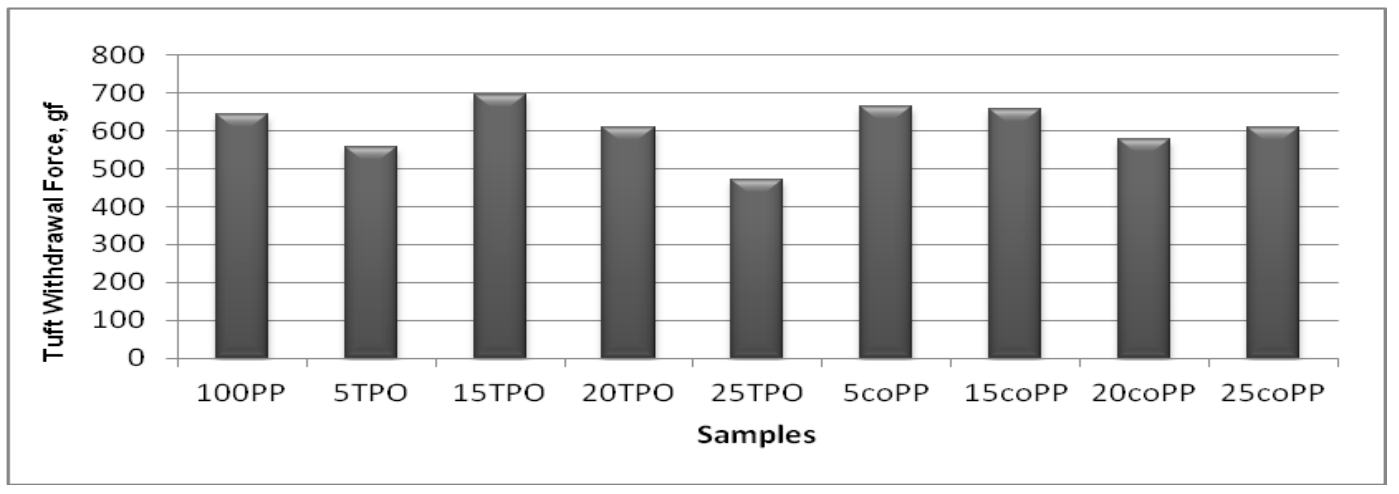

Figure 10. Tuft withdrawal forces of samples

Table 16. Mean, standard deviation and \%CV of tuft withdrawal force test results

\begin{tabular}{ccccccccccc}
\hline Sample code & & 100PP & 5TPO & 15TPO & 20TPO & 25TPO & 5coPP & 15coPP & 20coPP & 25coPP \\
\hline $\begin{array}{c}\text { Tuft } \\
\text { withdrawal }\end{array}$ & Mean & 644 & 556 & 696 & 610 & 470 & 665 & 657 & 579 & 610 \\
force & SD & 186.22 & 211.81 & 335.07 & 293.54 & 243.69 & 346.46 & 347.45 & 238.28 & 309.32 \\
& \%CV & 28.91 & 38.09 & 48.14 & 48.12 & 51.85 & 52.09 & 52.88 & 41.15 & 50.70 \\
\hline
\end{tabular}

Table 17. Two-way ANOVA for tuft withdrawal force of TPO or coPP mixed samples.

\begin{tabular}{lcccccc}
\hline Source & Type IV Sum of Squares & df & Mean Square & F & Sig. & Partial Eta Squared \\
\hline Corrected Model & $718717.500 \mathrm{a}$ & 7 & 102673.929 & 1.180 & 0.317 & 0.052 \\
Intercept & 58636622.500 & 1 & 58636622.500 & 674.052 & 0.000 & 0.816 \\
content_type & 80102.500 & 1 & 80102.500 & 0.921 & 0.339 & 0.006 \\
\%_percentage & 379087.500 & 3 & 126362.500 & 1.453 & 0.230 & 0.028 \\
content_type *\%_percentage & 259527.500 & 3 & 86509.167 & 0.994 & 0.397 & 0.019 \\
Error & 13222660.000 & 152 & 86991.184 & - & - & - \\
Total & 72578000.000 & 160 & - & - & - & - \\
Corrected Total & 13941377.500 & 159 & - & - & - & - \\
\hline
\end{tabular}


in other word higher toughness. It was also determined that, as the $\%$ percentage increased, percentage compression recovery, work of compression and recovery decreased, while percentage work recovery increased. This result confirmed that, coPP and TPO enhanced the toughness property of mixed samples, as stated in some studies in the literature [23-25]. In addition, the amount of coPP or TPO in PP homopolymer changed internal structure, therefore pile yarns showed different load carrying performances.

Hexapod test assessments exhibited that coPP mixed samples had better texture retention than those of TPO. This can be interpreted as coPP had better appearance retention than TPO. On the other hand, no linear relationship was observed between $\%$ percentages of mixes.

\section{REFERENCES}

1. Crawshaw GH. 2002. Carpet Manufacture. New Zealand: Wronz Developments.

2. Gong RH. 2011. Specialist Yarn and Fabric Structures Developments and Applications. United Kingdom: Woodhead Publishing Limited.

3. Hannay F. 2002. Rigid Plastics Packaging - Materials, Processes and Applications. United Kingdom: Rapra Technology Limited.

4. Tripathi D. 2002. Practical Guide to Polypropylene. United Kingdom: Rapra Technology Limited.

5. Brydson JA. 1995. Thermoplastic Elastomers - Properties and Applications. United Kingdom: Rapra Technology Limited.

6. Massey LK. 2004. Film Properties of Plastics and Elastomers, A Guide to Nonwovens in Packaging Applications, Second Edition. United Kingdom: William Andrew Applied Science Publishers.

7. Grover G, Zhu S, Twilley IC. 1993. Dynamic Mechanical Properties of Carpet Yarns and Carpet Performance. Textile Research Journal, 63(5), 257-266.

8. Vangheluwe L, Kiekens P. 1997. Resilience Properties of Polypropylene Carpets. Textile Research Journal, 67(9), 671-676.

9. Laughlin KC, Cusick GE. 1968. Carpet Performance Evaluation Textile Research Journal, 38(1), 78-80.

10. Önder E, Berkalp ÖB. 2001. Effects of Different Structural Parameters on Carpet Physical Properties. Textile Research Journal, 71(6), 549555.

11. Koç E, Celik N, Tekin M. 2005. An Experimental Study on Thickness Loss of Wilton-Type Carpets Produced with Different Pile Material after Prolonged Heavy Static Loading. Part-I: Characteristics Parameters and Carpet Behaviour. FIBRES \& TEXTILES in Eastern Europe, 13(4), 56-62.

12. Koç E, Celik N. 2007. An Experimental Study on Thickness Loss of Wilton-Type Carpets Produced with Different Pile Material after Prolonged Heavy Static Loading. Part-II: Characteristics Parameters and Carpet Behaviour. FIBRES \& TEXTILES in Eastern Europe, 15(4), 87-92.

13. Çelik N, Koç E. 2010. Study on the Thickness Loss of Wilton-Type Carpets under Dynamic Loading. FIBRES \& TEXTILES in Eastern Europe, 18(1), 54-58.
Tuft withdrawal force results of samples showed that, content type and \% percentage had no significant effect. High variation was observed on withdrawal forces, and this was a probable result of unevenness of applied latex on the back of carpets.

\section{Acknowledgement}

This study was supported by the Scientific and Technological Research Council of Turkey (TÜBİTAK, under Grant No: 217M176), for which the authors would like to thank. They also wish acknowlodge Kartal Halı Tekstil San. Tic. A.Ş. and Royal Halı İplik Tekstil Mobilya San. Tic. A.Ş. for their technical support for production of yarn and carpet samples.

14. Korkmaz Y, Koçer SD. 2010. Polipropilen Makine Halısı Üretim Parametrelerinin Halı Performansına Olan Etkileri. Tekstil Teknolojileri Elektronik Dergisi, 4(1), 48-58.

15. Özdil N, Bozdoğan F, Özçelik Kayseri G, Süpüren Mengüç G. 2012. Compressibility and Thickness Recovery Characteristic of Carpet. Tekstil ve Konfeksiyon, 3, 203-211.

16. Dayiary M, Shaikhzadeh Najar S, Shamsi M. 2009. A New Theoretical Approach tu Cut-Pile Carpet Compression Based on Elastic-Stored Bending Energy. The Journal of the Textile Institute, 100(8), 688-694.

17. Dayiary, M, Shaikhzadeh Najar, S, Shamsi, M. 2010. An Experimental Verification of Cut-Pile Carpet Compression Behavior. The Journal of the Textile Institute, 101(6), 488-494.

18. Sarkeshick S, Tavanai H, Zarrebini M, Morshed M. 2009. An Investigation on the Effects of Heat-Setting Process on the Properties of Polypropylene Bulked Continuous Filament Yarns. The Journal of the Textile Institute, 100(2), 128-134.

19. Dadgar M, Merati AA, Varkiyani MH. 2015. Evaluation of Heat Setting Parameters in Carpet Comfort. Fibers and Polymers, 16(5), 1169-1176.

20. Kebabcı M, Babaarslan O, Özkan Hacıŏulları S, Telli A. 2015. The Effect of Drawing Ratio and Cross-Sectional Shapes on the Properties of Polypropylene CF and BCF Yarns. Tekstil ve Mühendis Dergisi, 22(100), 46-53.

21. Erdoğan ÜH. 2012. Effect of Pile Fiber Cross Section Shape on Compression Properties of Polypropylene Carpets. The Journal of the Textile Institute, 103(12), 1369-1375.

22. Tavanai H, Morshed M, Hosseini SM. 2003. Effect of On-Line Melt Blending of Polypropylene with Polyamide 6 on the Bulk and Strength of the Resulting BCF Yarn. Iranian Polymer Journal, 12(5), 421-430.

23. Lotti C, Correa CA, Canevarolo SV. 1999. Mechanical and Morphological Characterization of Polypropylene Toughened with Olefinic Elastomer. Materials Research, 3(2), 37-44.

24. Fasihi M, Mansouri H. 2016. Effect of Rubber Interparticle Distance Distribution on Toughening Behavior of Thermoplastic Polyolefin Elastomer Toughened Polypropylene. Journal of Applied Polymer Science, 133, 44068.

25. Rungswang $\mathrm{W}$, Saendee $\mathrm{P}$, Thitisuk $\mathrm{B}$, Pathaweeisariyakul T, Cheevasrirungruang W. 2013. Role of Crystalline Ethylene-Propylene Copolymer on Mechanical Properties of Impact Polypropylene Copolymer. Journal of Applied Polymer Science, 128, 3131-3140. 